\title{
PENDIDIKAN KESEHATAN (PERSONAL HYGIENE) TERHADAP TINGKAT PENGETAHUAN, SIKAP DAN TINDAKAN PERSONAL HYGIENE ANAK USIA SEKOLAH
}

\author{
Siti Mukaromah'), Katharina Menge ${ }^{2)}$ \\ Program Studi S1 IImu Keperawatan STIKES Wiyata Husada Samarinda \\ Email : s.mukharomah2014@gmail.com
}

\begin{abstract}
ABSTRAK
Anak usia sekolah rentan terhadap infeksi yang timbul akibat kurangnya pemahaman dan respon maupun tindakan tentang personal hygiene. Masalah kesehatan yang sering muncul akibat tidak menjaga personal hygiene berupa karies gigi, kutu rambut, cacingan, diare, bahkan gangguan psikologis, sebagaimana yang terjadi pada siswa sekolah dasar negeri 016 Samarinda Ulu yang kurang memperhatikan personal hygiene baik kebersihan kulit rambut, kuku tangan dan kaki, kulit, pakaian, gigi dan mulut. Untuk mengetahui perbedaan tingkat pengetahuan, sikap dan tindakan personal hygiene anak usia sekolah sebelum dan sesudah pendidikan kesehatan (personal hygiene). Rancangan penelitian kuantitatif menggunakan desain pre-eksperimental dengan pendekatan one-group pre-test-post-test design. Penelitian ini menggunakan 66 responden. Penelitian dilakukan pada bulan Desember 2018, dengan menggunakan skala guttmen dan likert serta uji Friedman dan uji Post Hoc Wilcoxon. Hasil penelitian diperoleh nilai $p$ value $=0,000$ dengan demikian value lebih kecil dari alpha 0,05 maka Ha diterima. Ada perbedaan tingkat pengetahuan, sikap dan tindakan anak usia sekolah sebelum dan sesudah pemberian pendidikan kesehatan (personal hygiene), maka pihak sekolah maupun orangtua dapat melakukan pendidikan kesehatan tentang personal hygiene kepada anak usia sekolah dengan berbagai metode dan dilakukan secara berkesinambungan agar dapat menjadi kebiasaan positif anak usia sekolah.
\end{abstract}

Kata Kunci : Pendidikan Kesehatan, Personal Hygiene

\section{PENDAHULUAN}

Anak usia sekolah merupakan kelompok khusus yang rentan terhadap masalah kesehatan. Masalah kesehatan pada anak usia sekolah sering berkaitan dengan personal hygiene atau kebersihan perorangan mencakup kebersihan kulit rambut, kebersihan kuku tangan dan kaki, kebersihan kulit, kebersihan pakaian, kebersihan gigi dan mulut, dan perawatan tubuh secara keseluruhan. Ketidakmampuan dalam menjaga personal hygiene, seseorang akan mudah mengalami infeksi.

Kurangnya pengetahuan tentang personal hygiene, kurangnya respon terhadap personal hygiene, dan kurangnya tindakan dalam menjaga personal hygiene menyebabkan gangguan fisik, meliputi: karies gigi, kutu merupakan salah satu tindakan personal hygiene, dapat meningkatkan prevalensi penyakit diare, cacingan, dan penyakit infeksi saluran pernapasan akut (ISPA) serta gangguan psikologi pada anak seperti tidak merasa nyaman, merasa malu dan lain-lain. Meningkatnya prevalensi penyakit tersebut dapat menyebabkan penyakit yang serius di kalangan anak usia sekolah, bahkan menjadi sebab kematian pada populasi anak sekolah (Mukono HJ, 2016).

Berdasarkan data Badan Kesehatan Dunia World Health Organization (WHO) (2015), sebanyak 100.000 anak Indonesia meninggal dunia karena penyakit diare setiap tahunnya. Anak usia sekolah yang menderita penyakit

\section{*Corresponding Author :}

Hestri Norhapifah

Program Studi S-1 Keperawatan

ITKES Wiyata Husada Samarinda, Indonesia

Email : s.mukharomah2014@gmail.com 
cacingan sebesar 40-60\% dan infeksi saluran pernapasan akut sebesar $20 \%$.

Berdasarkan data Profil Kesehatan Provinsi Kalimantan Timur (2016), Kalimantan Timur termasuk Provinsi dengan angka kejadian diare yang cukup tinggi tercatat ada $92,19 \%$, dan 4,34\% masalah kulit. Masalah kebersihan yang masih banyak dialami oleh anak usia sekolah yaitu, masalah pada gigi sebanyak $86 \%$, tidak bisa memotong kuku sebanyak $53 \%$, tidak bisa menggosok gigi sebanyak $42 \%$, dan tidak mencuci tangan sebanyak $8 \%$. Sedangkan penyakit yang banyak diderita oleh anak usia sekolah yaitu penyakit cacingan sebesar $60-80 \%$, dan karies gigi sebanyak $74,4 \%$. Berdasarkan data Riset Kesehatan Dasar (Riskesdas) Nasional tahun 2018 untuk kesehatan gigi dan mulut, proporsi masalah gigi dan mulut sebesar $57,6 \%$ (Kemenkes RI, 2018). Semua masalah yang terjadi pada anak usia sekolah terjadi karena kurangnya pengetahuan, respon dan perilaku terhadap kebersihan diri.

Pendidikan kesehatan merupakan upaya atau kegiatan menciptakan perilaku masyarakat yang kondusif, sehingga individu mampu menyadari cara memelihara kesehatan dan menghindari hal-hal yang merugikan kesehatan (Notoadmodjo, 2014). Tindakan pendidikan kesehatan bagi anak usia sekolah diperkenalkan melalui program usaha kesehatan sekolah (UKS) yang bertujuan meningkatkan kemampuan hidup sehat seluruh warga sekolah maupun lingkungannya.

Metode pendidikan kesehatan yang dapat dilakukan pada anak usia sekolah, diantaranya metode ceramah dan demonstrasi. Metode ceramah merupakan penerapan dan penuturan secara lisan dengan menggunakan alat bantu mengajar, sedangkan metode demonstrasi merupakan pertunjukan tentang proses terjadinya suatu peristiwa atau benda sampai pada penampilan tingkah laku yang dicontohkan agar dapat diketahui dan dipahami oleh peserta didik (Sabri, 2015).

Hasil studi pendahuluan yang dilakukan pada tanggal 13 Oktober 2018 dengan melakukan wawancara terhadap 10 siswa di SDN 016 Samarinda Ulu dengan mengajukan *Corresponding Author :

Hestri Norhapifah

Program Studi S-1 Keperawatan

ITKES Wiyata Husada Samarinda, Indonesia

Email : s.mukharomah2014@gmail.com pertanyaan-perrtanyaan berkaitan dengan personal hygiene didapatkan data bahwa seluruh siswa tidak mengetahui tentang apa itu personal hygiene atau kebersihan diri, cara melakukan personal hygiene dengan baik dan benar, maupun tujuan dari personal hygiene. Observasi yang dilakukan pada 10 siswa tersebut didapatkan data siswa mencuci tangan hanya dengan air mengalir saja tanpa menggunakan sabun, kuku panjang dan tidak dipotong, pakaian tidak rapih dan kurang bersih, gigi kotor, kulit kepala kurang bersih, serta banyak yang berjalan tanpa menggunakan alas kaki. Didapatkan pula informasi dari pihak sekolah tentang kegiatan yang pernah dilakukan terkait personal hygiene yaitu adanya penyuluhan dari puskesmas setempat, namun hanya sebatas informasi tentang mencuci tangan.

\section{METODE PENELITIAN}

Rancangan penelitian ini adalah penelitian kuantitatif menggunakan desain pre-eksperimental dengan pendekatan one-group pre-test-post-test design. Sampel dalam penelitian anak usia sekolah kelas III sebanyak 66 siswa di SDN 016 Samarinda Ulu dengan teknik total sampling. Data diperoleh melalui kuesioner. Teknik analisis data yang digunakan terdiri dari analisis univariat dan bivariat. Analisis univariat menjelaskan masing-masing variabel yang diteliti, sedangkan analisis bivariat menggunakan uji Friedman.

\section{HASIL DAN PEMBAHASAN \\ TABEL 1 \\ DISTRIBUSI KARAKTERISTIK RESPONDEN}

\begin{tabular}{lcc}
\hline Karakteristik Responden & Frekuensi & (\%) \\
\hline Umur & & \\
\hline 8 tahun & 25 & 37.9 \\
9 tahun & 37 & 56.1 \\
10 tahun & 3 & 4.5 \\
11 tahun & 1 & 1.5 \\
\hline Total & 66 & 100 \\
\hline Jenis Kelamin & & \\
\hline
\end{tabular}


Jurnal Medika Karya IImiah Kesehatan

Vol 5, No.1. 2020

ISSN : 2654-945X (Online), 2541-4615 (Print)

Journal homepage : http://jurnal.itkeswhs.ac.id/index.php/medika

\begin{tabular}{lcc}
\hline Laki-laki & 32 & 48.5 \\
Perempuan & 34 & 51.5 \\
\hline Total & 66 & 100 \\
\hline Kelas & & \\
\hline Kelas A & 31 & 47 \\
Kelas B & 35 & 53 \\
\hline Total & 66 & 100 \\
\hline
\end{tabular}

Didapatkan mayoritas responden berumur 9 tahun yaiitu sebanyak 37 siswa $(56,1 \%)$, berjenis kelamin perempuan sebanyak 34 siswa $(51,5 \%)$. Perbedaan jumlah siswa di kedua kelas tidak terlalu signifikan, yaitu kelas B sebanyak 35 siswa (53\%) dan kelas A sebanyak 31 siswa (47\%). Pada fase ini, anak usia sekolah cenderung untuk berpikir konkrit dan meniru sehingga membutuhkan role model yang mampu memberikan gambaran jelas terkait perilaku.

TABEL 2

DISTRIBUSI RESPONDEN BERDASARKAN TINGKAT PENGETAHUAN SEBELUM PENDIDIKAN KESEHATAN

\begin{tabular}{ccc}
\hline Tingkat Pengetahuan & Frekuensi & (\%) \\
\hline Baik $(76-100 \%)$ & 26 & 39.4 \\
Cukup $(56-75 \%)$ & 36 & 54.5 \\
Kurang $(<56 \%)$ & 4 & 6.1 \\
\hline Total & 66 & 100 \\
\hline
\end{tabular}

Didapatkan mayoritas responden memiliki tingkat pengetahuan cukup sebelum diberikan pendidikan kesehatan tentang personal hygiene yaitu sebanyak 26 siswa $(39,4 \%)$. Adanya kegiatan penyuluhan kesehatan yang pernah dilakukan di sekolah mempengaruhi pengetahuan siswa tentang kesehatan, meskipun tidak dilakukan secara berkesinambungan.

TABEL 3

DISTRIBUSI RESPONDEN BERDASARKAN TINGKAT PENGETAHUAN SESUDAH PENDIDIKAN KESEHATAN

\begin{tabular}{ccc}
\hline Tingkat Pengetahuan & Frekuensi & (\%) \\
\hline Baik $(76-100 \%)$ & 65 & 98.5 \\
Cukup (56-75\%) & 1 & 1.5
\end{tabular}

Didapatkan mayoritas responden memiliki tingkat pengetahuan baik sesudah diberikan pendidikan kesehatan tentang personal hygiene yaitu sebanyak 65 siswa (98,5\%). Pendidikan kesehatan yang dilakukan tidak hanya sekedar metode ceramah tetapi juga dengan metode demonstrasi dapat meningkatkan antusias siswa dalam belajar serta memudahkan siswa untuk praktik secara langsung.

TABEL 4

DISTRIBUSI RESPONDEN BERDASARKAN SIKAP SEBELUM PENDIDIKAN KESEHATAN

\begin{tabular}{ccc}
\hline Sikap & Frekuensi & (\%) \\
\hline Positif & 36 & 54.5 \\
Negatif & 30 & 45.5 \\
\hline Total & 66 & 100 \\
\hline
\end{tabular}

Didapatkan mayoritas responden memiliki sikap positif sebelum diberikan pendidikan kesehatan tentang personal hygiene yaitu sebanyak 36 siswa (54,5\%). Anak usia sekolah mampu belajar sebagaimana apa yang mereka lihat, dengar, maupun rasa, sehingga mempengaruhi sikap dalam menyikapi suatu informasi yang didapat.

TABEL 5

DISTRIBUSI RESPONDEN BERDASARKAN SIKAP SEBELUM PENDIDIKAN KESEHATAN

\begin{tabular}{ccc}
\hline Sikap & Frekuensi & (\%) \\
\hline Positif & 47 & 71.2 \\
Negatif & 19 & 28.8 \\
\hline Total & 66 & 100 \\
\hline
\end{tabular}

Didapatkan jumlah responden memiliki sikap positif sesudah diberikan pendidikan kesehatan tentang personal hygiene semakin bertambah yaitu sebanyak 47 siswa $(71,2 \%)$. Informasi kesehatan yang diberikan secara berkelanjutan mampu mempengaruhi sikap anak usia sekolah menjadi lebih positif.

\section{*Corresponding Author :}

Hestri Norhapifah

Program Studi S-1 Keperawatan

ITKES Wiyata Husada Samarinda, Indonesia

Email : s.mukharomah2014@gmail.com 


\begin{tabular}{lcr}
\hline \multicolumn{3}{c}{ TABEL 6} \\
DISTRIBUSI & RESPONDEN & BERDASARKAN \\
TINDAKAN & SEBELUM & PENDIDIKAN \\
KESEHATAN & & \\
& &
\end{tabular}

\begin{tabular}{ccc}
\hline Tindakan & Frekuensi & (\%) \\
\hline Baik & 42 & 63.6 \\
Kurang Baik & 24 & 36.4 \\
\hline Total & 66 & 100 \\
\hline
\end{tabular}

Didapatkan mayoritas responden memiliki tindakan yang baik sebelum diberikan pendidikan kesehatan tentang personal hygiene yaitu sebanyak 42 siswa $(54,5 \%)$. Anak usia sekolah mampu mengulang suatu tindakan yang pernah dilihat, oleh karena itu adanya peran guru maupun orangtua dalam mengajarkan suatu tidakan yang baik terutama terkait kesehatan dapat menjadi pembelajaran praktik langsung bagi anak usia sekolah.

TABEL 7

DISTRIBUSI RESPONDEN BERDASARKAN TINDAKAN SESUDAH PENDIDIKAN KESEHATAN

\begin{tabular}{ccc}
\hline Tindakan & Frekuensi & $(\%)$ \\
\hline Baik & 66 & 100 \\
\hline Total & 66 & 100 \\
\hline
\end{tabular}

Didapatkan seluruh responden yaitu sebanyak 66 siswa (100\%) memiliki tindakan yang baik sesudah diberikan pendidikan kesehatan tentang personal hygiene. Informasi kesehatan yang diberikan secara berkelanjutan dengan metode gabungan yaitu ceramah dan demonstrasi mampu meningkatkan kemampuan siswa dalam melakukan suatu tindakan terutama terkait personal hygiene.

TABEL 8

ANALISIS PERBEDAAN TINGKAT PENGETAHUAN, SIKAP, DAN TINDAKAN SEBELUM DAN SESUDAH PENDIDIKAN KESEHATAN (PERSONAL HYGIENE)

\begin{tabular}{ccc}
\hline Variabel & $\begin{array}{c}\text { Median } \\
(\text { Min-Max })\end{array}$ & Nilai $p$ \\
\hline
\end{tabular}

\section{*Corresponding Author :}

Hestri Norhapifah

Program Studi S-1 Keperawatan

ITKES Wiyata Husada Samarinda, Indonesia

Email : s.mukharomah2014@gmail.com

\begin{tabular}{lcc}
\hline Pengetahuan & $17(7-21)$ & \\
Sikap & $57(14-72)$ & $0,000^{\star}$ \\
Tindakan & $13(8-15)$ & \\
\hline${ }^{*}$ Signifikan $(p<0,05)$ & Uji Fridmen
\end{tabular}

Hasil uji Friedman dengan tingkat kesalahan (alpha) 0,05, diperoleh nilai signifikan sebesar $p$ value $=0,000$ yang berarti kurang dari alpha $(0,05)$, maka dapat disimpulkan terdapat perbedaan tingkat pengetahuan, sikap, dan tindakan sebelum dan sesudah pendidikan kesehatan (personal hygiene). Selanjutnya dilakukan uji analisa post hoc wilcoxon untuk mengetahui selisih perbedaan tingkat pengetahun, sikap dan tindakan sebelum dan sesudah pendidikan kesehatan (personal hygiene).

TABEL 9

SELISIH PERBEDAAN TINGKAT PENGETAHUAN, SIKAP, DAN TINDAKAN SEBELUM DAN SESUDAH PENDIDIKAN KESEHATAN (PERSONAL HYGIENE)

\begin{tabular}{|c|c|c|c|}
\hline & & $\mathrm{N}$ & $p$ Value \\
\hline \multirow{4}{*}{$\begin{array}{l}\text { Post Penge- } \\
\text { tahuan - Pre } \\
\text { Pengetahuan }\end{array}$} & $\begin{array}{l}\text { Negative } \\
\text { Ranks }\end{array}$ & $0^{\mathrm{a}}$ & \multirow{4}{*}{$0,000^{*}$} \\
\hline & $\begin{array}{l}\text { Positive } \\
\text { Ranks }\end{array}$ & $66^{b}$ & \\
\hline & Ties & $0^{c}$ & \\
\hline & Total & 66 & \\
\hline \multirow[t]{4}{*}{$\begin{array}{l}\text { Post Sikap - } \\
\text { Pre Sikap }\end{array}$} & $\begin{array}{l}\text { Negative } \\
\text { Ranks }\end{array}$ & $16^{d}$ & \multirow{4}{*}{$0,000^{*}$} \\
\hline & $\begin{array}{l}\text { Positive } \\
\text { Ranks }\end{array}$ & $39^{e}$ & \\
\hline & Ties & $11^{\dagger}$ & \\
\hline & Total & 66 & \\
\hline \multirow{5}{*}{$\begin{array}{l}\text { Post } \\
\text { Tindakan - } \\
\text { Pre Tindakan }\end{array}$} & Negative & 29 & \multirow{5}{*}{$0,000^{*}$} \\
\hline & Ranks & $3^{9}$ & \\
\hline & $\begin{array}{l}\text { Positive } \\
\text { Ranks }\end{array}$ & $56^{h}$ & \\
\hline & Ties & $7^{i}$ & \\
\hline & Total & 66 & \\
\hline
\end{tabular}

*Signifikan $(p<0,05)$ Uji Wilcoxon

Hasil uji post hoc Wilcoxon menunjukkan dari 66 responden didapatkan selisih perbandingan 
pada tingkat pengetahuan sebelum dengan sesudah pendidikan kesehatan (personal hygiene) mengalami peningkatan sebanyak 66 responden. Sikap sebelum dengan sesudah pendidikan kesehatan (personal hygiene) mengalami peningkatan yaitu yang bersikap positif 39 responden, 16 responden masih bersikap negatif dan 11 belum mengalami perubahan sikap. Sedangkan tindakan mengami perubahan sebelum dan sesudah pendidikan kesehatan (personal hygiene) sebanyak 56 responden yang bertindak baik, 3 responden yang bertindak kurang baik dan 7 responden tidak mengami perubahan tindakan. Hasil analisis uji wilcoxon menunjukkan adanya perubahan tingkat pengetahuan, sikap dan tindakan personal hygiene dengan $p$ value $0,000<0,05$, maka Ha diterima dan Ho ditolak, dapat disimpulkan bahwa terdapat perbedaan tingkat pengetahuan, sikap dan tindakan personal hygiene siswa kelas III SDN 016 Samarinda Ulu sebelum dan sesudah tindakan pendidikan kesehatan (personal hygiene).

\section{Pengaruh pendidikan kesehatan (personal hygiene) dengan tingkat pengetahuan, sikap, dan tindakan personal hygiene}

Hasil analisis data pada tabel 8 perbedaan tingkat pengetahuan, sikap, dan tindakan personal hygiene sebelum dan sesudah pendidikan kesehatan (personal hygiene) di SDN 016 Samarinda Ulu diperoleh nilai $p$ value $=0,000$ dan nilai alpha 0,05 . Nilai $p<\alpha$ maka $\mathrm{Ha}$ diterima, dengan demikian terdapat perbedaan tingkat pengetahuan, sikap, dan tindakan sebelum dan sesudah pendidikan kesehatan (personal hygiene).

Rentang nilai tingkat pengetahuan sebesar $7-21$ dengan nilai median sebesar 17. Hal ini menunjukkan bahwa rata-rata siswa mengalami peningkatan pengetahuan sebesar 17 poin. Rentang nilai sikap sebesar $14-72$ dengan nilai median sebesar 57. Hal ini menunjukkan bahwa rata-rata siswa mengalami peningkatan sikap sebanyak 57 poin. Sedangkan rentang nilai tindakan sebesar 8-15 dengan nilai median sebesar 13 . Hal ini menunjukkan bahwa rata-rata siswa *Corresponding Author :

Hestri Norhapifah

Program Studi S-1 Keperawatan

ITKES Wiyata Husada Samarinda, Indonesia

Email : s.mukharomah2014@gmail.com mengalami peningkatan tindakan sebanyak 13 poin. Sehingga dapat disimpulkan bahwa ada peningkatan pengetahuan, sikap dan tindakan setelah diberikan pendidikan kesehatan dengan metode ceramah dan demonstrasi.

Hal ini sesuai dengan penelitian yang dilakukan oleh Farah (2014) dan Trisnawati (2013) menunjukan bahwa responden mengalami perubahan dan peningkatan pengetahuan dan sikap yang signifikan setelah diberikan pendidikan kesehatan. Hal ini seiring dengan pendapat Notoatmojdo (2012) bahwa pendidikan kesehatan merupakan suatu upaya atau kegaitan untuk menciptakan perilaku masyarakat yang kondusif untuk kesehatan, yang artinya bahwa pendidikan kesehatan berupaya agar masyarakat tahu individu menyadari atau mengetahui bagaimana cara memelihara kesehatan mereka, bagaimana menghindari atau mencegah hal-hal yang merugikan kesehatan mereka dan kesehatan orang lain dan sebagainya.

Hasil analisis lanjutan pada tabel 9 selisih perbedaan tingkat pengetahuan, sikap, dan tindakan sebelum dan sesudah pendidikan kesehatan (personal hygiene) menunjukkan seluruh responden (100\%) mengalami peningkatan pengetahuan. Anak usia sekolah mampu mengakses informasi dari apa yang dilihat, didengar maupun dirasa. Informasi berupa pendidikan kesehatan yang disampaikan secara langsung melalui metode ceramah dan diajarkan langsung melalui metode demonstrasi mampu meningkatkan pemahaman siswa terkait materi yang diajarkan.

Jumlah responden yang mengalami peningkatan sikap sebanyak 39 responden, sebanyak 16 responden masih bersikap negatif dan 11 responden belum mengalami perubahan sikap. Hal ini dipengaruhi oleh berbagai faktor diantaranya minat, pengalaman, maupun budaya sekitar. Anak usia sekolah terutama usia 8 - 9 tahun masih bersifat labil dan pemikiran konkrit. Pada fase ini, anak usia sekolah mencari role model yang sekiranya dapat menjadi gambaran sikap dan pada akhirnya untuk ditiru. Oleh karena itu perlu adanya sosok yang mampu menunjukkan 
peran positif baik orangtua maupun guru, sehingga anak mampu mengambil sikap yang lebih baik.

Adapun jumlah responden yang mengalami peningkatan dalam tindakan sebanyak 56 responden, 3 responden masih bertindak kurang baik dan 7 responden tidak mengalami perubahan tindakan. Sama halnya dengan sikap, tindakan dipengaruhi oleh beberapa faktor, terutama informasi dan budaya sekitar. Apa yang diajarkan oleh orang yang lebih tua maupun orang kebanyakan apalagi sifatnya berulang maka akan terekam dengan baik di otak anak sehingga mempengaruhi tindakan selanjutnya. Adanya gambaran anak yang mampu meningkatkan tindakan positifnya, adanya anak yang belum mampu bertindak lebih baik, atau anak yang masih dalam kondisi sama bukan berarti tidak mampu untuk bertindak lebih baik lagi. Fase anak usia sekolah merupakan salah satu tahapan proses kehidupan sehingga anak usia sekolah akan terus berkembang sesuai dengan masanya.

Hal ini sesuai dengan Notoadmodjo (2012) yang menyatakan bahwa faktor-faktor yang mempengaruhi pengetahuan adalah pendidikan, umur, minat, pengalaman, kebudayaan lingkungan sekitar, serta informasi dan metode yang digunakan. Faktor yang mempengaruhi dalam penelitian ini secara langsung yaitu informasi dan metode yang digunakan, dimana informasi yang diterima anak usia sekolah didapatkan dari pendidikan kesehatan yang dilakukan melalui metode ceramah dan demontrasi. Informasi tentang personal hygiene kepada siswa dapat meningkatkan pengetahuan, sikap, dan tindakan. Hasil penelitian diketahui bahwa sebelum diberikan pendidikan kesehatan siswa masih kurang mengetahui tentang personal hygiene dengan benar dan setelah diberikan pendidikan kesehatan pengetahuan, sikap,dan tindakan siswa bertambah.

\section{SIMPULAN}

Analisis pengaruh pendidikan kesehatan (personal hygiene) dengan tingkat pengetahuan, sikap, dan tindakan personal hygiene di SDN 016 Samarinda Ulu dilakukan *Corresponding Author :

Hestri Norhapifah

Program Studi S-1 Keperawatan

ITKES Wiyata Husada Samarinda, Indonesia

Email : s.mukharomah2014@gmail.com dengan menggunakan uji Friedman dan Post Hoc Wilcoxon diperoleh nilai $p$ value $=0,000$ dengan demikian value lebih kecil daripada alpha 0,05, maka Ha diterima yang berarti dapat disimpulkan bahwa terdapat perbedaan antara tingkat pengetahuan, sikap, dan tindakan personal hygiene sebelum dan sesudah pendidikan kesehatan (personal hygiene). Saran, diharapkan pihak sekolah dapat memberikan pendidikan kesehatan tentang personal hygiene kepada siswa dengan menggunakan metode ceramah dan demontrasi setiap satu kali seminggu, sehingga siswa dapat mengetahui manfaat dari menjaga personal hygiene yang telah diberikan oleh pihak sekolah dan siswa dapat melakukan personal hygiene dengan baik. Diharapkan pula orang tua untuk selalu memperhatikan personal hygiene anak dengan mengajarkan kepada anak seperti mandi 2 kali sehari, mencuci tangan sebelum dan sesudah makan, menggosok gigi sesudah makan dan sebelum tidur serta memeriksa kuku anak seminggu sekali.

\section{DAFTAR PUSTAKA}

Arikunto. (2013). Prosedur Penelitian. Jakarta: Rineka Cipta.

Balitbang Kemenkes RI. (2018). Riset Kesehatan Dasar; RISKESDAS. Jakarta: Balitbang Kemenkes RI.

Dahlan, Sopiyudin. (2014). Statistik Untuk Kedokteran Dan Kesehatan Edisi 6. Jakarta : Salmba Medika.

Dinas Kesehatan Provinsi Kalimantan Timur. (2016). Profil Kesehatan Tahun 2015. Samarinda : Dinas Kesehatan Provinsi Kalimantan Timur.

Farah, et. all. (2014). Pengaruh Pendidikan Kesehatan tentang Personal Hygiene terhadap pengetahuan dan sikap Siswa SDN Rembes 1 Dusun Watugimbal Semarang. Skripsi.

Kemenkes RI. (2018). Profil Kesehatan Indonesia th 2018. Jakarta : Kemenkes RI

Mukono HJ. (2016). Prinsip Dasar Kesehatan Lingkungan (Edisi kedua). Surabaya: Airlangga University Press. 
Jurnal Medika Karya IImiah Kesehatan

Vol 5, No.1. 2020

ISSN : 2654-945X (Online), 2541-4615 (Print)

Journal homepage : http://jurnal.itkeswhs.ac.id/index.php/medika

Notoatmojdo, S. (2012). Promosi Kesehatan dan Perilaku Kesehatan. Jakarta: PT Rineka Cipta.

Notoatmodjo, S. (2014). IImu Perilaku Kesehatan. Jakarta: Rineka Cipta.

Sabri M. A. (2015). Psikologi pendidikan. Pedoman Ilmu Jaya : Jakarta.

Trisnawati, dkk (2013). Pengaruh Penyuluhan Personal Hygiene Terhadap Pengetahuan Mengenai Personal Hygiene Pada Murid Kelas IV SDN Pampang Kec. Panakkukang Kota Makassar. Skripsi.

WHO. (2015). Pencegahan dan Pengendalian Infeksi Saluran Pernapasan Akut (ISPA) yang Cenderung Menjadi Epidemi dan Pandemi di Fasilitas Pelayanan Kesehatan. Geneva: Alih Bahasa: Trust Indonesia.

*Corresponding Author :

Hestri Norhapifah

Program Studi S-1 Keperawatan

ITKES Wiyata Husada Samarinda, Indonesia

Email : s.mukharomah2014@gmail.com 